Provided for non-commercial research and education use. Not for reproduction, distribution or commercial use.

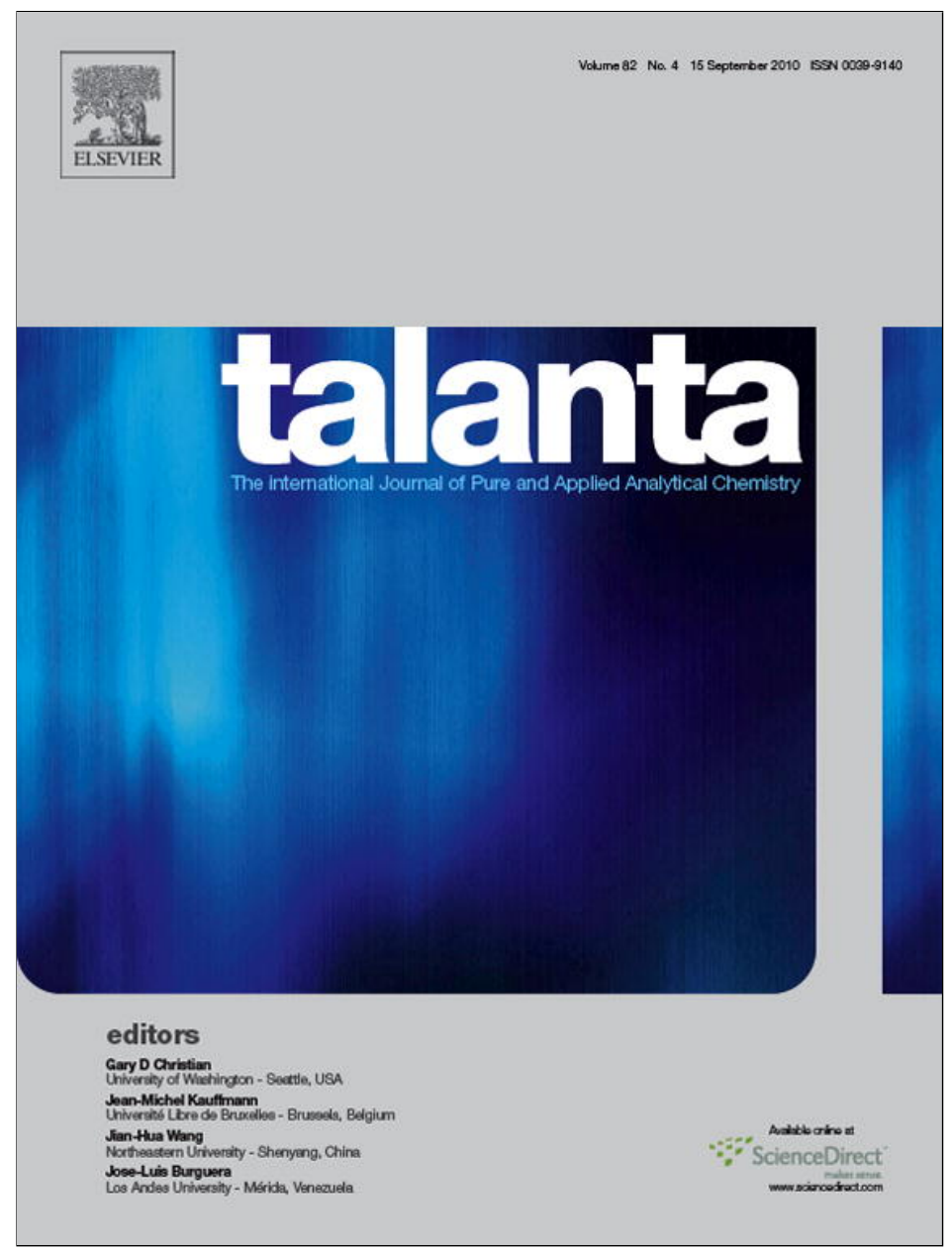

This article appeared in a journal published by Elsevier. The attached copy is furnished to the author for internal non-commercial research and education use, including for instruction at the authors institution and sharing with colleagues.

Other uses, including reproduction and distribution, or selling or licensing copies, or posting to personal, institutional or third party websites are prohibited.

In most cases authors are permitted to post their version of the article (e.g. in Word or Tex form) to their personal website or institutional repository. Authors requiring further information regarding Elsevier's archiving and manuscript policies are encouraged to visit:

http://www.elsevier.com/copyright 


\title{
Extraction and concentration of vapors from fire debris for forensic purposes: Evaluation of the use of Radiello Passive Air Sampler
}

\author{
S. Baechler*, S. Comment, O. Delémont \\ Ecole des Sciences Criminelles, University of Lausanne, Batochime, CH-1015 Lausanne, Switzerland
}

\section{A R T I C L E I N F O}

\section{Article history:}

Received 18 March 2010

Received in revised form 3 June 2010

Accepted 28 June 2010

Available online 4 July 2010

\section{Keywords}

Arson

Forensic investigation

Ignitable liquids

Passive headspace

Gas chromatography-mass spectrometry

\begin{abstract}
A B S T R A C T
The Radiello Passive Air Sampler is one of the latest innovations developed for the sampling of pollutants in the air by passive headspace. It has been reported that its properties allow an enhanced sensitivity, reproducibility and adsorption capacity. It therefore appears to be of interest in the extraction of potential residues of ignitable liquids present in fire debris when arson is suspected.

A theoretical approach and several laboratory tests have made it possible to precisely characterize in a forensic perspective the potential of the device in extracting and concentrating the vapors of ignitable liquids found in fire debris. Despite some advantages, the Radiello device appears to be less efficient than traditional axial symmetry samplers.
\end{abstract}

(c) 2010 Elsevier B.V. All rights reserved.

\section{Introduction}

In a fire scene, the presence of inexplicable substances which could facilitate the ignition or accelerate fire propagation points towards the hypothesis that the incident results from a deliberate act. These substances, mainly ignitable liquids, are intended to burn efficiently and only faint traces will remain caught in the fire debris. One of the missions of the investigators on the scene is to search and collect debris liable to contain traces of volatile ignitable compounds which may be extracted, concentrated and identified.

Several techniques for sample preparation have been developed and validated for the extraction and concentration of volatile traces from fire debris. However, none of them is ideal due to the large range of chemical and physical properties found in ignitable liquids, but also because their traces matrix is often decomposed or even carbonized [1,2].

Solvent extraction [3] is one of the oldest methods used in fire and arson scene examination. The solvent has to be evaporated from the sample extract in order to achieve good sensitivity. This method is very efficient for nonvolatile products or for a matrix that retains strongly the ignitable products, however it tends to produce complex chromatograms due to the co-extraction of compounds from the matrix.

\footnotetext{
* Corresponding author. Tel.: +41 2169246 54; fax: +41 216924605

E-mail address: simon.baechler@unil.ch (S. Baechler).
}

The more widely used headspace techniques are preferred due to better sensitivity and the reduced risk of co-extracting compounds from the matrix. Headspace techniques all lay on the principle of extracting and concentrating the vapor phase from above the sample by using an airtight and heated container. The ignitable liquid vapors are then collected on an adsorbent by either natural convection or forced flows. Passive headspace extraction [4] is defined by natural and passive diffusion of vapors onto the surface of the adsorbent by using activated charcoal strip (ACS) or solid phase microextraction (SPME) [5] in the case of a fire debris analysis. Vacuum driven flows or pulsed helium flows can also be used to force volatile compounds onto the adsorbent material; this is the principle of dynamic headspace extraction [6]. SPME and dynamic headspace extraction methods are more sensitive compared to passive headspace extraction, but it is very difficult to conduct additional analysis and the original state of the sample is lost, which in a forensic perspective makes any counter expertise impossible. Passive headspace extraction with ACS does not share this drawback since the strip may be cut in two parts after having been exposed to the headspace; one part is then analyzed while the other is preserved as an archive [2]. Furthermore, the ACS passive headspace extraction technique is considered very sensitive as quantifiable vapors can be extracted from volumes as low as $0.1 \mu \mathrm{L}$ of ignitable liquids from the debris. These reasons explain why ACS is one of the most widely used passive headspace extraction techniques for fire debris analysis.

Improvements in passive headspace methods and the development of new solutions are aiming not only to simplify and 
accelerate the extraction process but also to improve its sensitivity and reproducibility. These last two key aspects are the reason why a study of the Radiello Air Sampler was undertaken.

\section{Principles}

The Radiello Passive Air Sampler (referred to hereafter as Radiello) is a headspace device developed by the Fondazione Salvatore Maugeri (Padova, Italy) to meet the requirements of ever more precise measurements in air pollution monitoring and workplace air hygiene control [7]. The quantities of analytes adsorbed on the device can be used to calculate the concentrations of pollutants thanks to Fick's law in its simplified form:

$C=\frac{m}{t Q} \quad$ with $Q=D\left(\frac{S}{l}\right)$

where $C$ is the concentration in air $\left(\mu \mathrm{g} \mathrm{m}^{-3}\right), m$ the adsorbed mass $(\mu \mathrm{g}), t$ the sampling time ( $\mathrm{min}), Q$ the sampling rate $\left(\mathrm{m}^{3} \mathrm{~min}^{-1}\right), D$ the diffusion coefficient $\left(\mathrm{m}^{2} \mathrm{~min}^{-1}\right), S$ the diffusive surface (membrane which protects the adsorbent surface) $\left(\mathrm{m}^{2}\right)$ and $l$ the distance between the diffusive surface and adsorbent surface ( $\mathrm{m}$ ).

This relation helps to enlighten the parameters which influence the sensitivity of a passive headspace device. The sampling time $t$ does not depend on a specific sampler and neither does $D$ which depends on sampled substances. Thus, to enhance the adsorbed quantity, either $S$ can be increased or $l$ can be decreased; these two parameters tightly rely on the device's geometry and dimensions.

The parameter $l$ cannot be decreased lower than $8 \mathrm{~mm}$ or else the diffusion law is not valid for weak air speed. In the case of the classical axial geometry found in passive samplers (such as ACS protected by a diffusive membrane), the adsorbing and diffusive surfaces are parallel, plane, and at a constant distance. Increasing the diffusive surface $S$ will thus necessarily increase the adsorbing surface. However, a greater quantity of solvent is then needed to desorb the analyte and dilution cancels any gain from a higher sampling rate.

With this in mind and considering the limitations in the choice of $l$, the solution brought by the Radiello device to increase the sampling rates for better sensitivity was to modify the geometry of the sampler by changing the plane symmetry to a radial one. A cylindrical adsorbent cartridge is placed in the center of a greater coaxial cylinder which acts as the diffusive surface or barrier. This results in a greater diffusive surface than the adsorbing one while keeping the distance between both surfaces constant. Molecules thus have a $360^{\circ}$ access upon contact with the cylinders for adsorption onto the cartridge.

Three basic elements thus constitute the Radiello device:

- an adsorbing cartridge: four different types exist depending on which type of pollutants is to be adsorbed. Cartridge code 130 is of interest for a fire investigation because it is designed for volatile organic compounds (VOCs). The cartridge (diameter: $5.8 \mathrm{~mm}$; height: $60 \mathrm{~mm}$ ) consists of a stainless steel grid filled with $530 \pm 30 \mathrm{mg}$ of activated carbon 35-50 mesh.

- a diffusive body: it is hydrophobic with a diameter of $16 \mathrm{~mm}$ and a height of $60 \mathrm{~mm}$. The body code 120 is designed for VOCs desorbed by solvent (compatible with code 130 cartridges). The body's polyethylene wall has a thickness of $1.7 \mathrm{~mm}$ and a porosity of $25 \pm 5 \mu \mathrm{m}$. The diffusive path is therefore $18 \mathrm{~mm}$.

- a supporting plate on which the diffusive body is screwed.

Radiello's radial geometry supposedly enables superior sampling rates compared to devices with an axial geometry, thus the sensitivity should be enhanced. Data published by the United Kingdom Health and Safety Laboratory and by Oury et al. [8-10]

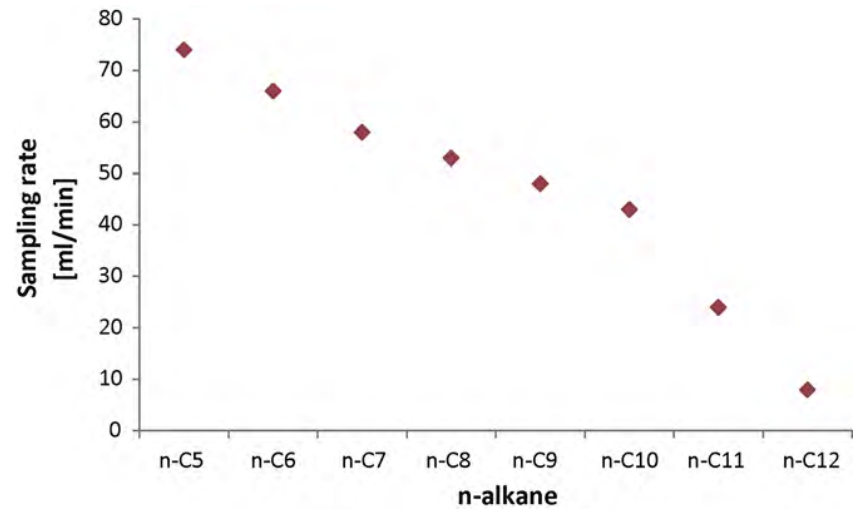

Fig. 1. Sampling rates representation for $n$-alkanes on the basis of data published by $[8-10]$.

confirms this assertion for very volatile pollutants. On the other hand Radiello's sensitivity decreases rapidly with decreasing compound volatility. Sampling rates obtained for a set of n-alkanes illustrate this tendency (Fig. 1).

Radiello's sensitivity thus appears to depend on the substances' volatility. This in turn could affect the capacity of the device to properly extract the less volatile compounds of ignitable residues from the fire debris. This severe drawback could be balanced by the fact that Radiello's measures are highly reproducible - in particularly by varying conditions in humidity, analytes concentrations, atmosphere composition and temperature [8,11-13].

With its $530 \pm 30 \mathrm{mg}$ of activated carbon, Radiello's cartridge possesses an adsorbent quantity superior to other devices (generally between 150 and $500 \mathrm{mg}$ ) [10]. The Activated Charcoal Strip of the DFLEX (Diffusive Flammable Liquid Extraction) device, commonly used for fire residues sampling, is of approximately $320 \mathrm{~mm}^{2}$ $(8 \mathrm{~mm} \times 20 \mathrm{~mm}$, two faces) which produces an adsorbing surface of about $1090 \mathrm{~mm}^{2}$ (cylinder of $5.8 \mathrm{~mm} \times 60 \mathrm{~mm}$ ). Studies have shown that the DFLEX saturation threshold is reached when fire debris contains between 25 and $30 \mu \mathrm{L}$ of a standard accelerant [14]. On the other hand, Radiello's saturation threshold can thus be estimated to be between 85 and $100 \mu \mathrm{L}$.

These advantages of the Radiello device and some of its environmental monitoring applications foreshadow how an introduction of the device to fire debris analysis could be advantageous. This is corroborated by previous research: Bhugwant et al. [15] used Radiello to measure the distribution of benzene and toluene concentrations in the vicinity of petrol stations that arises from the filling and discharging of tankers, as well as the filing of private cars. Carrieri et al. [16] retained sampling with Radiello as the method of reference to control the biological indicators efficiency in measuring the occupational exposure of gas-station employees to benzene.

However, it is important to point out that passive headspace operating conditions applied to the sampling of fire debris are significantly different from the ones generally used in air quality analysis. Fire debris may contain light to heavy ignitable compounds, while the majority of environment applications are aimed at detecting pollutants which are highly volatile (BTEX: benzene, toluene, ethylbenzene and xylenes). Furthermore, the usual sampling temperature (ranging between 60 and $90^{\circ} \mathrm{C}$ ) is far more elevated than the ambient one, the volume of the vapor phase is very limited and quasi stagnant, and there is a competition between the adsorbent and the matrix of the fire debris (especially if carbonized). While air monitoring applications most often exceed a day, the sampling time for fire debris analysis generally ranges from 8 to $18 \mathrm{~h}$.

Despite having properties that are theoretically interesting, the uncharacterized behavior of Radiello in these very specific 


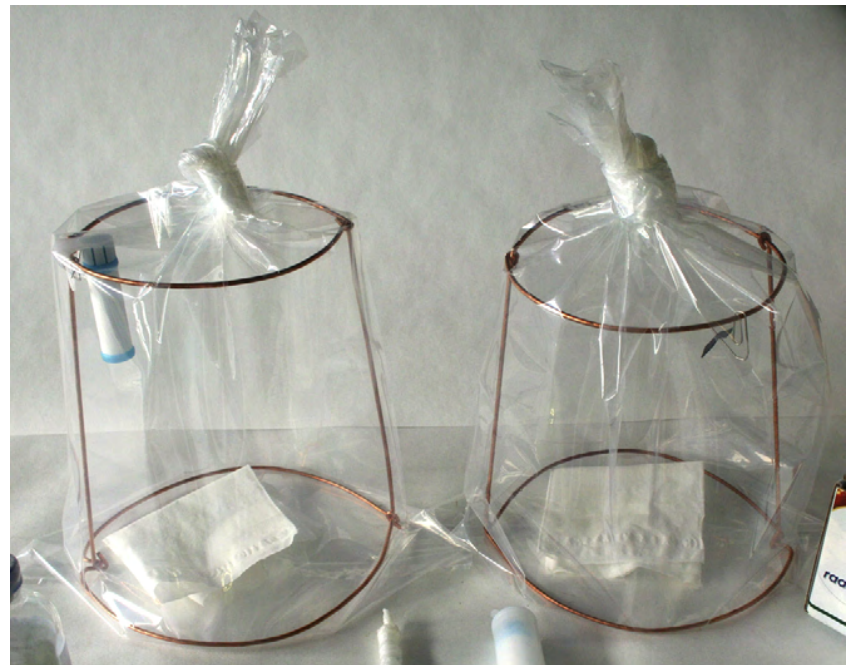

Fig. 2. Passive headspace extraction preparation with a Radiello device (left) and an activated carbon strip (right).

conditions (variable volatility of ignitable compounds, sampling temperature and sampling time, air volume and air speed, adsorbent/fire debris matrix competition) and its differentiated sensitivity in function of compounds volatility raised the question for its application in fire debris analysis. In particular, the risk of encountering difficulties in extracting and concentrating the heaviest compounds of accelerants must be more precisely characterized.

\section{Material and methods}

The nature of this study is essentially comparative. Results obtained by Radiello were confronted with those obtained by an activated carbon strips (ACS) sampler whose capacities are well defined. Thus, the tests were performed in parallel with identical conditions. Five extractions with Radiello devices were compared to five extractions with ACS to assess the influence of one parameter: the quantity of ignitable liquid contained in the support matrix. It is important to add that the tests were conducted in conditions optimized for a sampling with ACS.

Materials, reagents and the analytical procedure that were used are presented below.

A standard accelerant mixture was prepared with a 1:2 mix of lead-free gasoline and diesel fuel purchased at a local tank station. Paper tissues (ordinary 100\% cellulose tissue, Artex, SCA Hygiene Products $\mathrm{GmbH}$, Mannheim, Germany) were placed in airtight nylon bags (bag C-64100, BVDA International, Haarlem, The Netherlands) to ensure the preservation of fire debris. A metal frame was also inserted into the bags in order to control the volume. Paper tissues were then respectively spotted with 1, 10, 50 and $100 \mu \mathrm{L}$ of the standard accelerant mixture. A passive headspace adsorbent (or sampler) was then placed in the bag hanging from the metal frame to prevent it from coming in contact with the paper tissue. The technical details of the two types of samplers used are as follows:

- Radiello: five "ready-to-use" code 123-1 devices (with code 130 adsorbing cartridges, code 120 diffusive bodies and support plates) ordered at Sigma-Aldrich (Switzerland).

- ACS: five activated carbon strips of $8 \mathrm{~mm} \times 20 \mathrm{~mm}$, purchased from Albrayco Laboratories Inc. (Cromwell, USA). ACS are suspended from the metal frame using metal clips.

The airtight nylon bags were then sealed by a knot and placed in an oven at $60^{\circ} \mathrm{C}$ for $16 \mathrm{~h}$ so that passive headspace extraction could occur [14]. Fig. 2 shows the preparation for both types of samplers.

Following the extraction process, the devices were desorbed according to the following conditions:

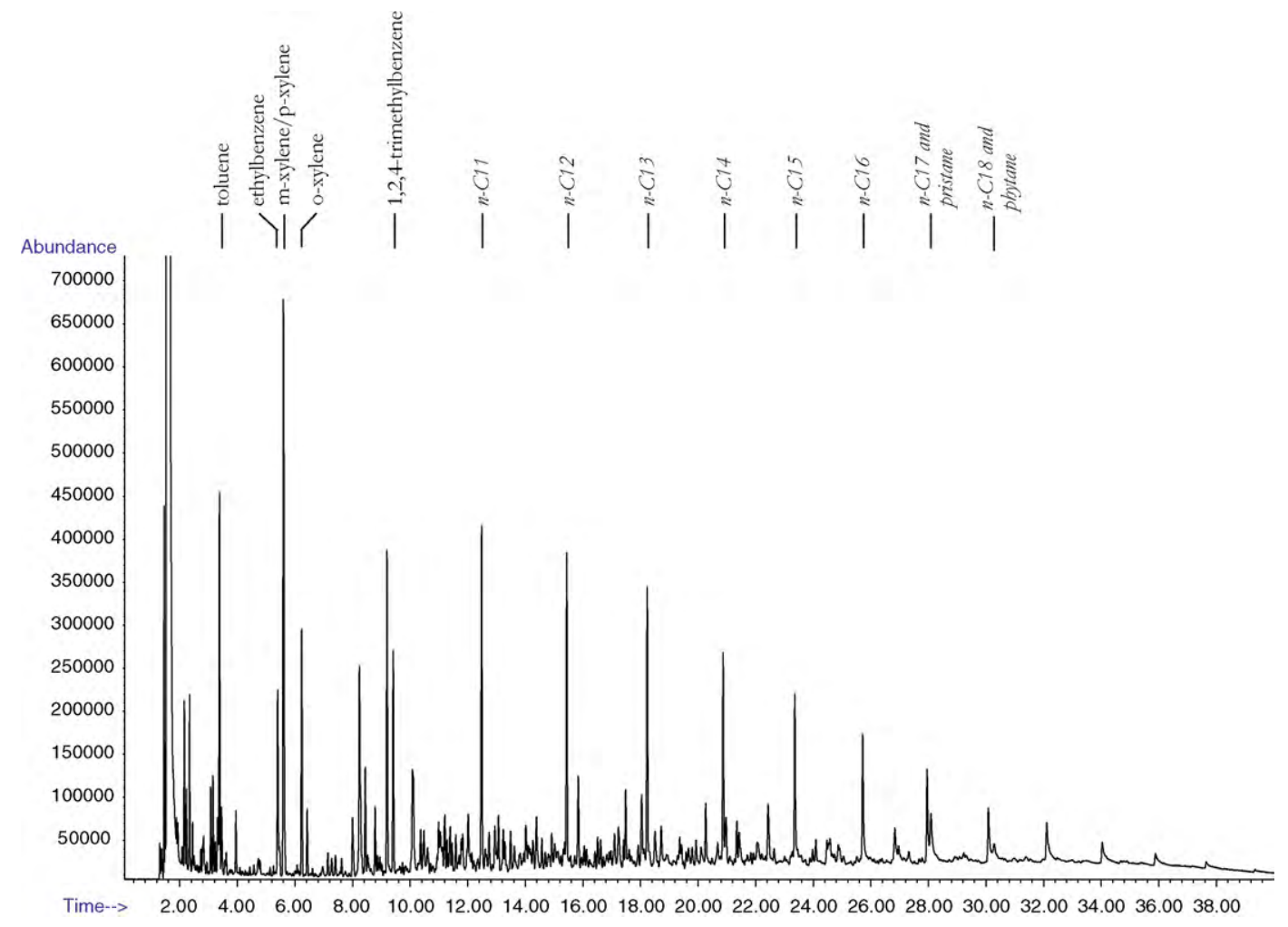

Fig. 3. Chromatogram obtained for the standard accelerant mixture. 

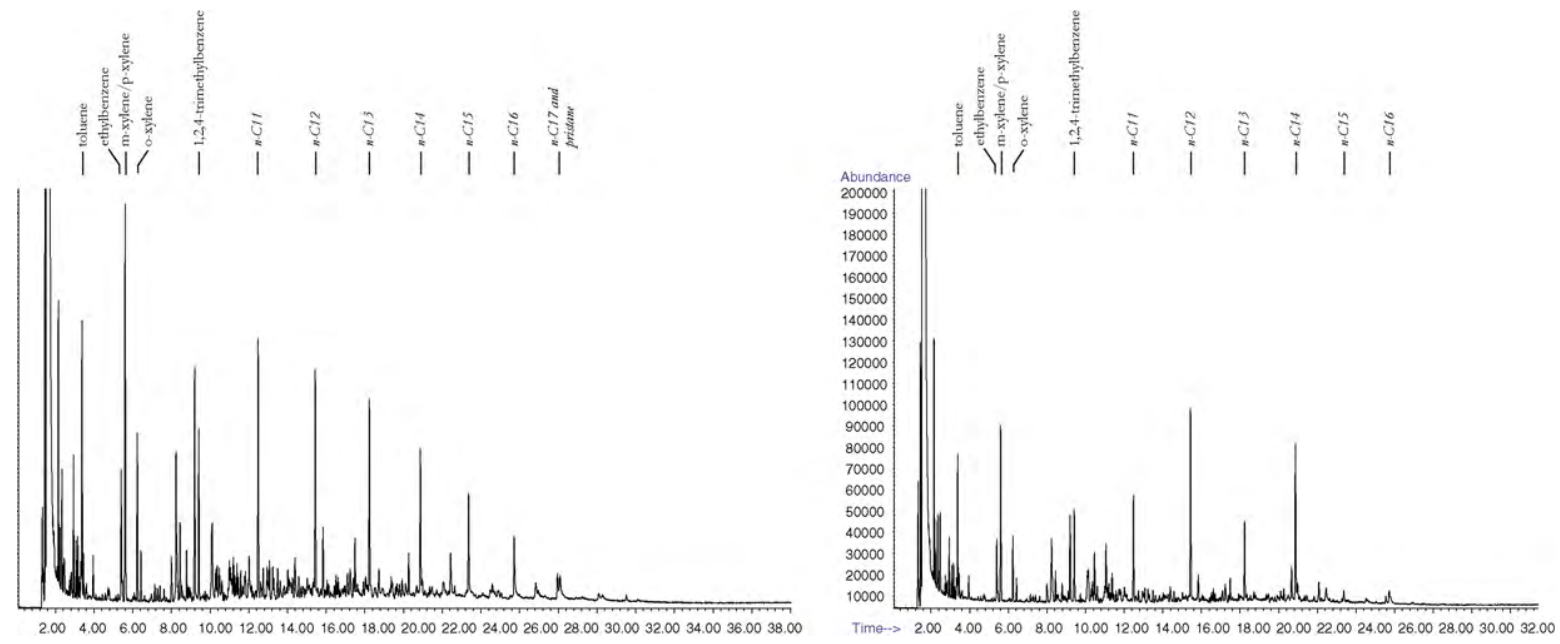

Fig. 4. Chromatogram obtained for $1 \mu \mathrm{L}$ of gasoline poured on a paper tissue: after ACS extraction (left) and Radiello extraction (right). The major aromatics compounds (plain) and n-alkanes (italic) are labeled.

- Radiello: the adsorbing cartridge is placed in a dedicated glass tube (supplied with the device) with $2000 \mu \mathrm{L}$ of $\mathrm{CS}_{2}$ (Fluka no. 84714, Sigma-Aldrich, Switzerland) and allowed to rest for 30 min (as recommended by the manufacturer) [7]. The solvent is then decanted in a $2 \mathrm{~mL}$ vial.

- ACS: desorption is directly undertaken in a $2 \mathrm{~mL}$ vial with $800 \mu \mathrm{L}$ $\mathrm{CS}_{2}$ (Fluka no. 84714, Sigma-Aldrich, Switzerland) and allowed to rest for $30 \mathrm{~min}$.

It must be emphasized that Radiello is desorbed with over twice as much $\mathrm{CS}_{2}$ as ACS $(2000 \mu \mathrm{L}$ vs. $800 \mu \mathrm{L})$. This difference could influence the total abundance in chromatograms. However, it was decided not to adjust the volume of solvent used for the desorption in order to evaluate the performances of both devices for the conditions recommended by previous researches $[7,14]$.

Following desorption, a GC-MS analysis was conducted: the eluents were analyzed with a gas chromatograph (Agilent Technologies $6890 \mathrm{~N}$ ) coupled with an inert mass spectrometer (Agilent Technologies 5975). The following parameters were selected: Column: HP-5MS, $30 \mathrm{~m} \times 0.25 \mathrm{~mm}$ i.d. with $0.25 \mu \mathrm{m}$ film thickness; carrier gas: helium at $1 \mathrm{~mL} \mathrm{~min}^{-1}$ constant flow; inlet temperature: $250^{\circ} \mathrm{C}$; volume injection: $1 \mu \mathrm{L}$ with $1: 25$ split ratio; oven program: $50^{\circ} \mathrm{C}$ isotherm for $3 \mathrm{~min}, 5^{\circ} \mathrm{C} \mathrm{min}-1$ up to $250^{\circ} \mathrm{C}$ and $250^{\circ} \mathrm{C}$ isotherm for $20 \mathrm{~min}$; mass spectrometer ionization source at $230^{\circ} \mathrm{C}$; mass quadrupole analyzer at $150^{\circ} \mathrm{C}$ in scan mode $(\mathrm{m} / \mathrm{z}$ $10-450$ ) with a sampling rate of $1.7 \mathrm{scan} / \mathrm{s}$.

\section{Results}

The chromatogram obtained for the standard accelerant mixture is presented first (Fig. 3).

Results are presented in the order of increasing quantity of standard accelerant mixture poured on paper tissues. The comments below relate to the total ion chromatograms (Figs. 4-7) with complementary observations made on specific extracted ion profiles of alkanes and aromatics (Figs. 8 and 9):

- $1 \mu \mathrm{L}$ (Fig. 4): Radiello's chromatogram stops at the level of n$C_{16}$ while the one for the ACS extends to the level of $n-C_{17}$ and pristane. Up to $24 \mathrm{~min}$, the same compounds are detected by both extraction devices but the proportions vary. For the Radiello device, the Gaussian distribution of n-alkanes is not noticeable because $n-C_{12}$ and $n-C_{14}$ are detected with a particularly large intensity. In the limit of observable peaks, the result for ACS reproduces the standard accelerant's chromatogram, while the proportions for alkanes significantly diverge for Radiello.

This is also true, but to a far lesser extent for relative proportions of aromatics. Radiello exhibits an intensity for toluene as high as for the peak corresponding to $\mathrm{m}$-xylene and $\mathrm{p}$-xylene (these last two coelute). However, a disequilibrium in the device's detection was noticed with Radiello between ethylbenzene and o-xylene in favor of the first, which is not the case for the standard and ACS chromatograms. On the other hand, trimethylbenzenes are detected in the same proportions for the Radiello, ACS and standard accelerant mixture.

- $10 \mu \mathrm{L}$ (Fig. 5): the sequence and relative proportions of the peaks detected for both extraction devices are very similar, except for the less volatile compounds. Radiello's chromatogram extends to the level of $n-C_{16}$ while the result for the ACS extends up to $n-C_{18}$ and phytane. However, the presence of the standard accelerant mixture can easily be assessed in the chromatograms obtained for both extraction devices.

Considering the extracted ion profiles for aromatics, the previous observation noticed with $1 \mu \mathrm{L}$ of accelerant mixture about the disequilibrium in the $C_{2}$-alkylbenzenes group (ethylbenzene, $\mathrm{m}$-xylene/p-xylene and o-xylene) in favor of ethylbenzene is also valid for Radiello and to a lesser degree for the ACS. The proportion between toluene and $\mathrm{m}$-xylene/p-xylene intensities is closer to the standard accelerant's reference chromatogram for Radiello than for the ACS. The profile of trimethylbenzenes is still well represented by both devices.

- $50 \mu \mathrm{L}$ (Fig. 6): the detection of highly volatile compounds is hindered when using passive headspace enrichment with ACS. This is due to the displacement of highly volatile compounds from their adsorption sites by less volatile compounds. Thus, in comparison with the chromatogram of the standard accelerant mixture and the results at $10 \mu \mathrm{L}$, the highly volatile compounds are detected with a weaker intensity. This phenomenon does not happen with the Radiello device as the proportions of the compounds match the ones of the standard accelerant mixture. On the other hand, the last detected peak with Radiello extraction is again $n-C_{16}$ whereas the ACS enables detection up to $n-C_{18}$ and phytane. For each peak detected in the analysis following extraction with Radiello and ACS, a ratio of the peak area normalized to the standard was calculated. As the ratio is strongly in favor of the Radiello for highly volatile compounds, it turns to be strongly in favor of ACS for less volatile compounds. 

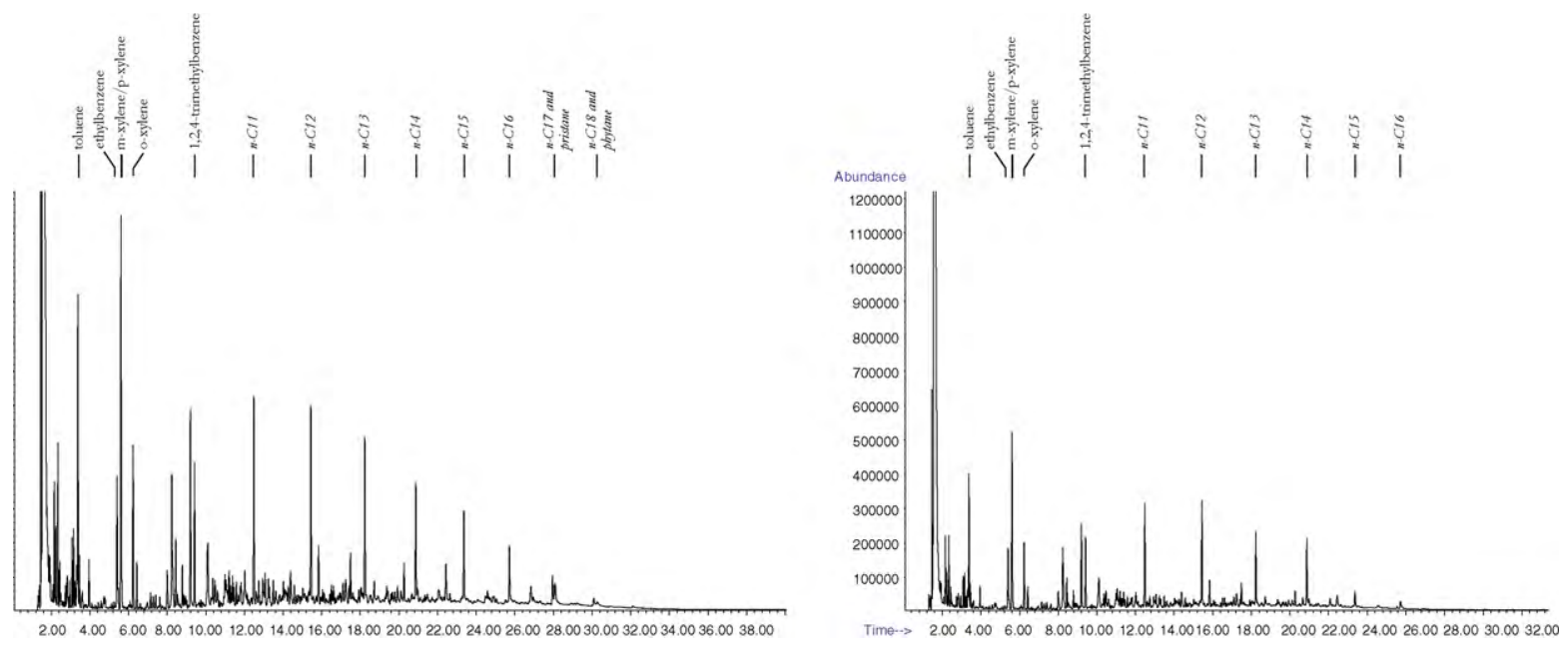

Fig. 5. Chromatogram obtained for $10 \mu \mathrm{L}$ of gasoline poured on a paper tissue: after ACS extraction (left) and Radiello extraction (right). The major aromatics compounds (plain) and n-alkanes (italic) are labeled.
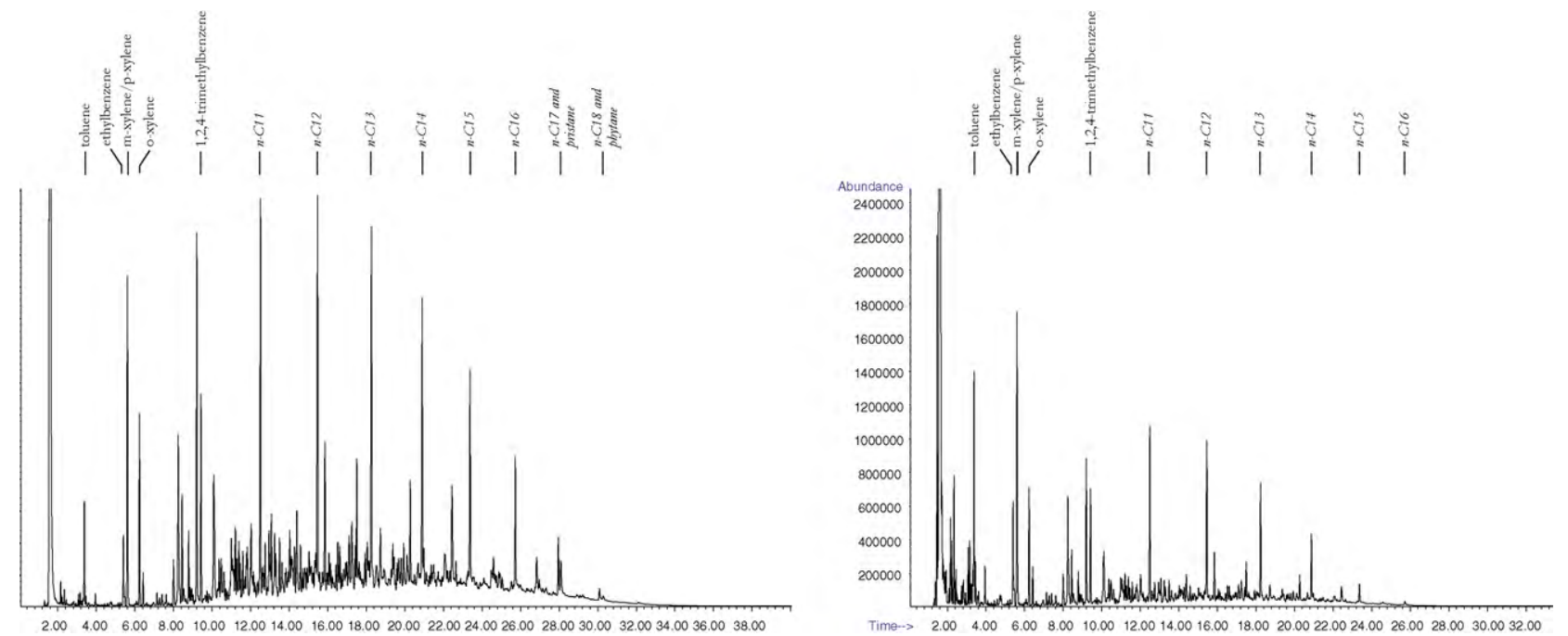

Fig. 6. Chromatogram obtained for $50 \mu \mathrm{L}$ of gasoline poured on a paper tissue: after ACS extraction (left) and Radiello extraction (right). The major aromatics compounds (plain) and n-alkanes (italic) are labeled.
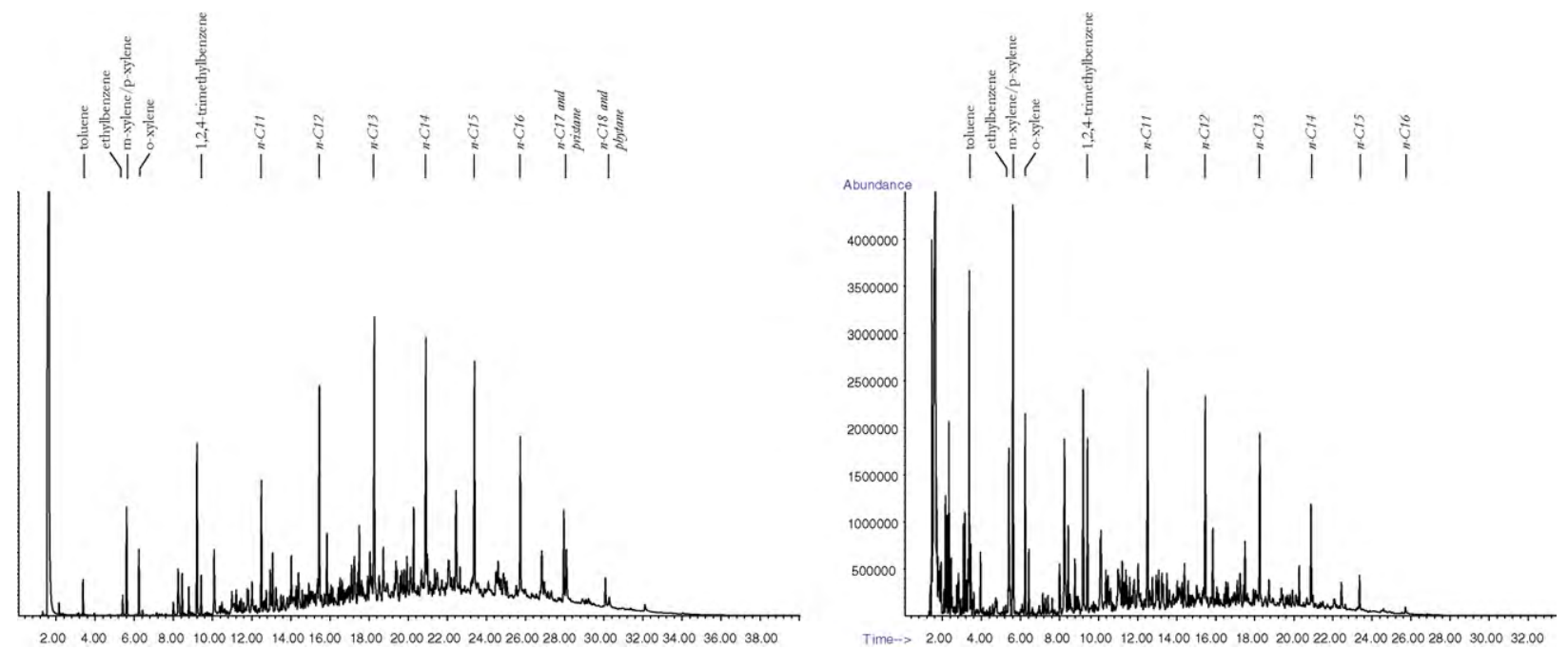

Fig. 7. Chromatogram obtained for $100 \mu \mathrm{L}$ of gasoline poured on a paper tissue: after ACS extraction (left) and Radiello extraction (right). The major aromatics compounds (plain) and n-alkanes (italic) are labeled. 

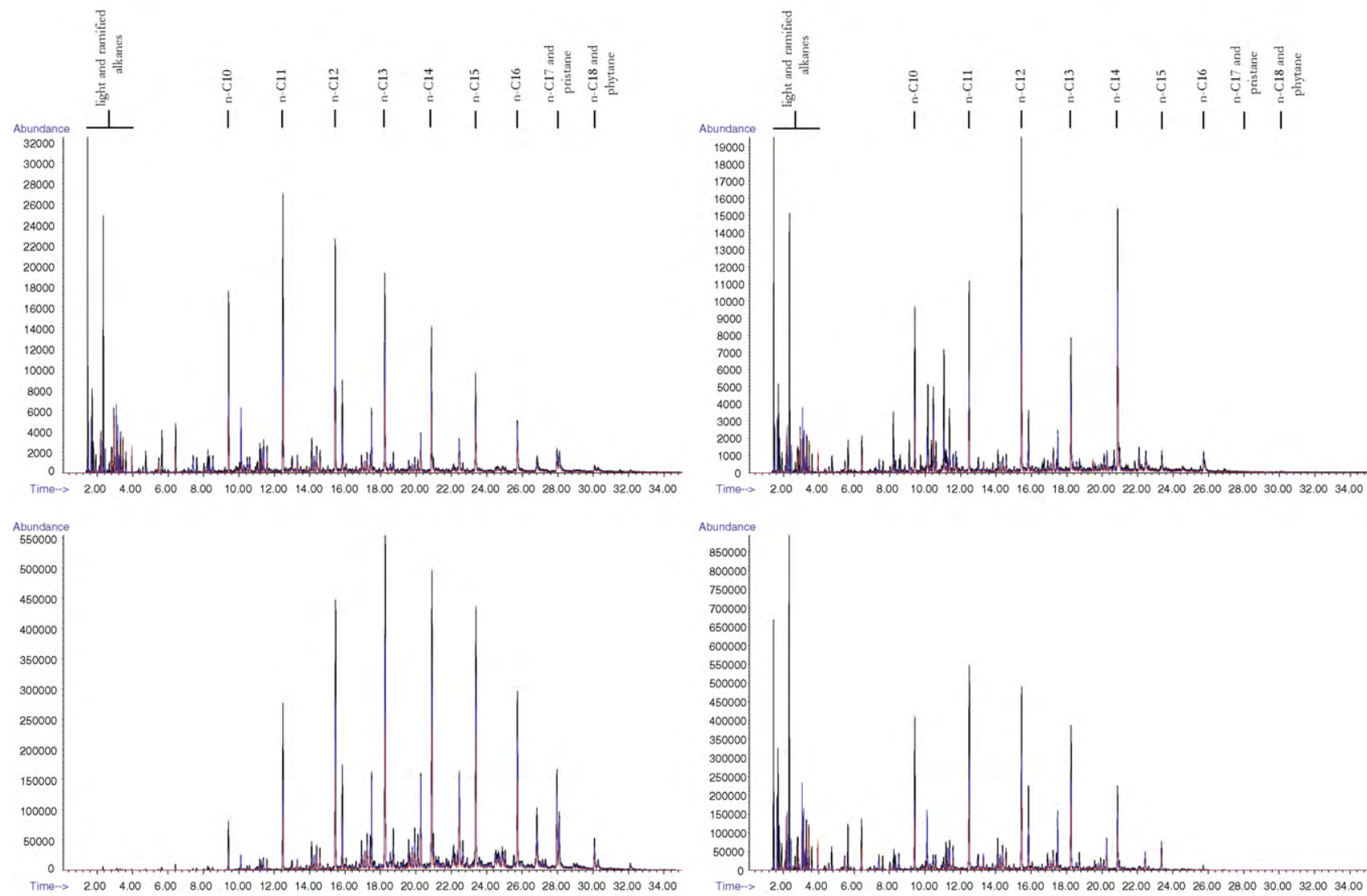

Fig. 8. Specific extracted ion profiles for alkanes after ACS extraction (left) and Radiello extraction (right): $1 \mu \mathrm{L}$ of standard accelerant mixture poured on the paper tissue (top) and $100 \mu \mathrm{L}$ (bottom). The major compounds are labeled. Ions (m/z): 57 (56.70-57.70); 71 (70.70-71.70); 85 (84.70-85.70).

The extracted aromatic ion profile for ACS is particularly affected by the phenomenon of displacement, showing major differences with the profile obtained after extraction with $10 \mu \mathrm{L}$ of standard accelerant mixture. In proportion to the $\mathrm{C}_{2}$-alkylbenzenes group (ethylbenzene, m-xylene/p-xylene and o-xylene), toluene decreases while trimethylbenzenes show a significant increase in terms of intensity. Ethylbenzene is noticeably lower than o-xylene, which is a direct effect of the shift in favor of less volatile compounds. This tendency was not observed with the Radiello device as the aromatic profile is very similar to the one obtained with $10 \mu \mathrm{L}$ of standard accelerant.

- $100 \mu \mathrm{L}$ (Fig. 7): the displacement observed at $50 \mu \mathrm{L}$ for the ACS is even more pronounced at $100 \mu \mathrm{L}$. Highly volatile compounds show a reduced intensity relative to the other compounds. Light branched alkanes disappear completely and the center of the Gaussian distribution of the n-alkanes is shifted from $\mathrm{n}-\mathrm{C}_{11}$ to $\mathrm{n}-\mathrm{C}_{13}$. Detection after ACS extraction extends up to $\mathrm{n}-\mathrm{C}_{19}$ while it stops again at $\mathrm{n}-\mathrm{C}_{16}$ for Radiello enrichment. No displacement is observed with Radiello and the chromatogram results are very similar to the standard accelerant mixture in terms of relative proportions, including the lightest compounds.

The extracted aromatic ion profile with ACS suffers in the same way from the displacement, the relative proportions of toluene, $\mathrm{C}_{2}$-alkylbenzenes and $\mathrm{C}_{3}$-alkylbenzenes being strongly altered. This is not the case for Radiello whose profile is similar to the ones obtained with lower quantities of standard accelerant mixture poured on the paper tissue.

\section{Discussion}

As expected from the technical data, Radiello is far less prone than ACS to the phenomenon of displacement. Up to a quantity of $100 \mu \mathrm{L}$, the saturation threshold was not reached and no bias affecting the highly volatile compounds in favor of the heaviest compounds could be observed. In contrast to the ACS, Radiello has shown an apparent stability in the chromatograms obtained after extractions of traces of increasing amount of standard accelerant mixture. In particular, the Radiello device could extract constant profiles for light branched alkanes and aromatics. Radiello's large adsorbing capacity could therefore be particularly interesting when analyzing fire debris prone to contain rich traces of ignitable liquids.

Under the conditions applied, passive headspace extraction with Radiello was unable to detect compounds heavier than $n-C_{16}$ regardless of the quantity of accelerant poured on paper tissues. A possible explanation for this effect could be the variable permeability of the polyethylene diffusive body to different VOCs. The thickness of this polyethylene wall is rather large $(1.7 \mathrm{~mm})$ and is likely causing some selective diffusion and/or adsorption which affects the mass transfer of VOCs through this wall. However, the link between the permeability of the polyethylene diffusive body of Radiello (thickness and porosity) and the volatility (boiling point) or chemistry (aliphatic/aromatic) of VOCs has not been documented or demonstrated and should be further studied. The absence of $\mathrm{n}-\mathrm{C}_{17} /$ pristane and $\mathrm{n}-\mathrm{C}_{18}$ /phytane doublets in the chromatograms obtained after extraction with this device could have a critical impact on the ability to detect and properly identify heavy petroleum distillates, especially with small traces of ignitable liq- 

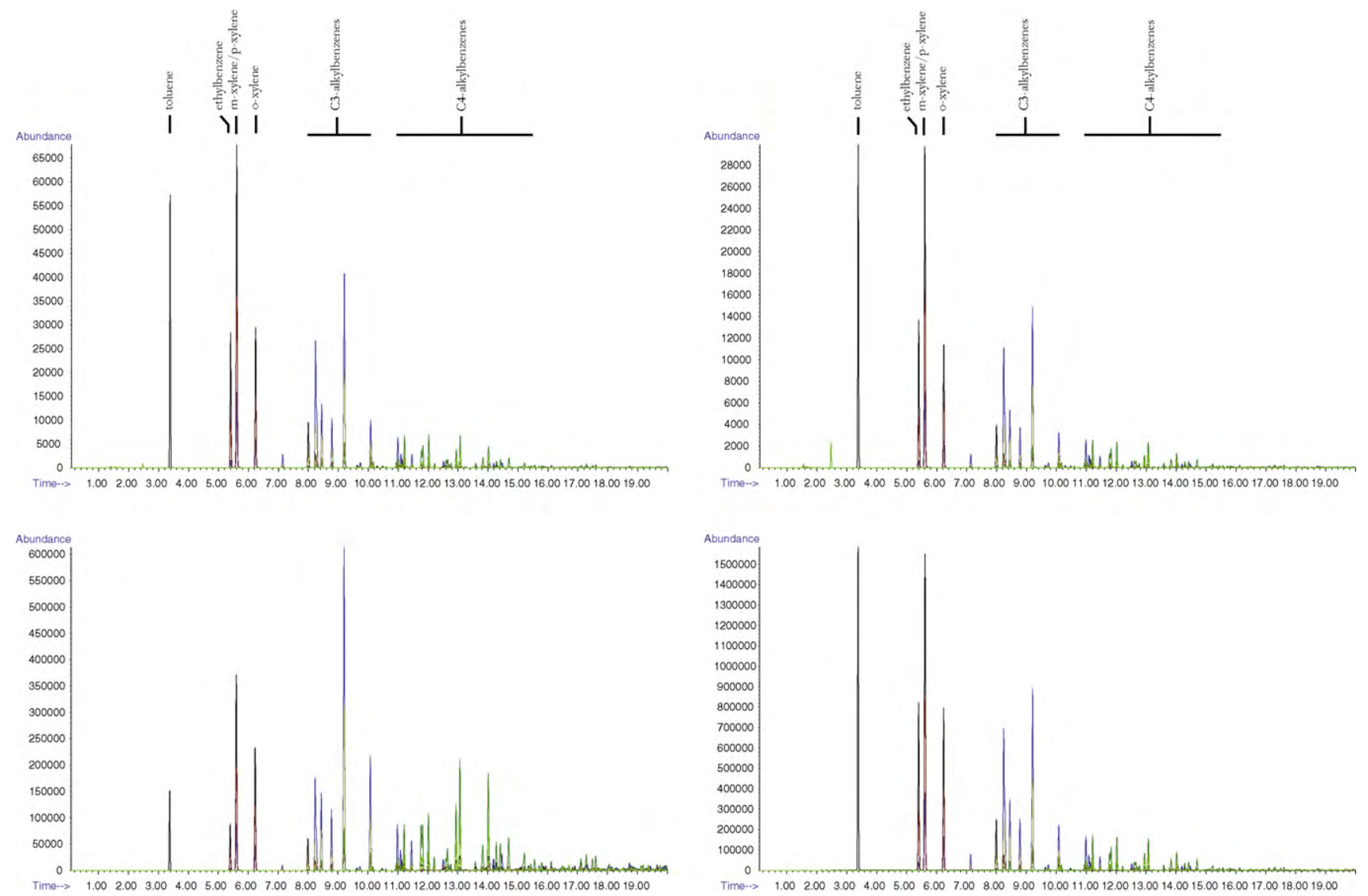

Fig. 9. Specific extracted ion profiles for aromatics after ACS extraction (left) and Radiello extraction (right): $1 \mu \mathrm{L}$ of standard accelerant mixture poured on the paper tissue (top) and $100 \mu \mathrm{L}$ (bottom). The major compounds are labeled. Ions (m/z): 91 (90.70-91.70); 105 (104.70-105.70); 106 (105.70-106.70); 119 (118.70-119.70); 120 (119.70-120.70); 134 (133.70-134.70).

uid. Passive headspace enrichment with ACS did not encounter these problems.

Although the compounds detected following extraction with Radiello present a global intensity that is inferior when compared to extraction with ACS, it is not possible to evaluate or assess their respective sensitivity solely on the basis of this limited set of experiments for which the sampling conditions were optimized for ACS. Further research is needed that could confirm the presumed stability demonstrated by the Radiello device throughout the whole set of studied concentrations.

\section{Acknowledgements}

The authors would like to thank Mr. Paolo Sacco, member of the Centro di Ricerche Ambientali of the Fondazione Salvatore Maugeri (Padova, Italy), for providing the scientific documentation needed to accomplish this study.

They also wish to thank the anonymous reviewers for their relevant and helpful comments, which contributed to improve and clarify the paper.

\section{References}

[1] Q. Ren, W. Bertsch, J. Forensic Sci. 44 (1999) 504

[2] A.D. Pert, M.G. Baron, J.W. Birkett, J. Forensic Sci. 51 (2006) 1033.

[3] American Society for Testing and Materials, ASTM E 1386-00 (2007)

[4] American Society for Testing and Materials, ASTM E 1412-00 (2007).

[5] American Society for Testing and Materials, ASTM E 2154-01 (2007).

[6] American Society for Testing and Materials, ASTM E 1413-06 (2007).

[7] Fondazione Salvatore Maugeri-IRCCS, Radiello's Manual, downloaded from http://www.radiello.com/english/download_en.htm.

[8] United Kingdom Health and Safety Laboratory, MDHS 88 (1997) 1.

[9] United Kingdom Health and Safety Laboratory, The Diffusive Monitor 12 (2001) 9.

[10] B. Oury, F. Lhuillier, J.C. Protois, Y. Moréle, J. Occup. Environ. Hyg. 3 (2006) 547.

[11] P. Bruno, M. Caputi, M. Caselli, G. de Gennaro, M. de Rienzo, Atmos. Environ. 39 (2005) 1347.

[12] B. Strandberg, A.L. Sunesson, M. Sundgren, J.O. Levin, G. Sällsten, L. Barregard, Atmos. Environ. 40 (2006) 7686.

[13] A. Pennequin-Cardinal, H. Plaisance, N. Locoge, O. Ramalho, S. Kirchner, J.C. Galloo, Atmos. Environ. 39 (2005) 2535.

[14] J.F. Demers-Kohls, S.L. Ouderkirk, J.L. Buckle, W.E. Norman, N.S. Catwright, C. Dagenais, Can. Soc. Forensic Sci. J. 27 (1994) 99.

[15] C. Bhugwant, B. Siéja, P. Sacco, Pollut. Atmos. 184 (2004) 455.

[16] M. Carrieri, E. Bonfiglio, M.L. Scapellato, I. Maccà, G. Tranfo, P. Faranda, E. Paci, G.B. Bartolucci, Toxicol. Lett. 162 (2006) 146. 